\title{
A Genetic Approach to Mapping the p53 Binding Site in the MDM2 Protein
}

\author{
Deborah A. Freedman, Charles B. Epstein, Judith C. Roth, and \\ Arnold J. Levine \\ Department of Molecular Biology, Princeton University, Princeton, \\ New Jersey, U.S.A.
}

\begin{abstract}
Background: The MDM2 oncoprotein binds to the tumor suppressor $\mathrm{p} 53$ and inhibits its anti-oncogenic functions.

Materials and Methods: To determine the amino acids of MDM2 that are critical for binding to p53, a modified two-hybrid screen was performed in yeast. Site-directed mutagenesis was then performed to identify MDM2 residues important for $\mathrm{p} 53$ interaction. Mutant MDM2 proteins were subsequently tested for their ability to bind to p53 in vitro and for their ability to regulate p53-mediated transcription in vivo.

Results: The yeast genetic screen yielded two $M d m 2$ mutations (G58D and C77Y) which disrupted binding to p53 in vitro without altering the conformation of MDM2 as determined with conformation-sensitive monoclonal antibodies. Site-directed mutagenesis yielded mutations
\end{abstract}

of two additional amino acids of MDM2 (D68 and V75) that prevented binding to p53 in vitro. The mutant MDM2 proteins were unable to inhibit p53-dependent transcription in vivo, which is consistent with prior indications that a physical interaction between the two proteins is required for MDM2's inhibition of p53. Finally, the crystal structure of the MDM2-p53 complex shows that two of the four critical residues identified here contact p53 directly, while the remaining two residues play important structural roles in the MDM2 domain.

Conclusions: MDM2 residues G58, D68, V75, and C77 are critical for MDM2's interaction with the $\mathrm{p} 53$ protein. Mutation of these residues to alanine prevents MDM2's interaction with p53 in vitro, and MDM2's regulation of p53's transcriptional activity in vivo.

\section{INTRODUCTION}

The $M d m 2$ oncogene was first identified as a gene amplified in a spontaneously transformed mouse 3T3 cell line, 3T3-DM (1). Overexpression of $M d m 2$ was then shown to be sufficient to cause immortalized mouse cell lines to be tumorigenic in nude mice (2). Furthermore, $M d m 2$ can immortalize primary rat embryo fibroblasts (REFs) alone and can transform REFs in cooperation with an activated ras gene (3). The human $M d m 2$ gene has been shown to be amplified or overex-

Address correspondence and reprint requests to: Arnold J. Levine, Department of Molecular Biology, Princeton University, Princeton, NJ 08544-1014, U.S.A. Tel: 609-2585990; Fax: 609-258-1704; e-mail: alevine@molbiol.princeton. edu.

Charles B. Epstein's current address: Department of Cell Biology and Neuroscience, University of Texas-Southwestern Medical Center, 5323 Harry Hines Blvd., Dallas, TX 75235.

Judith C. Roth's current address: Klinikum der Universität Marburg, ZIM, Gastroenterologie, Baldinger Str., 35033 Marburg, Germany. pressed at the mRNA level in a variety of human sarcomas, gliomas, carcinomas, and leukemias (4-12). In addition, enhanced translational efficiency has been shown to be responsible for overexpression of the MDM2 protein in some human choriocarcinoma cell lines (13), and normal tissue from a member of a cancer-prone family was shown to express high levels of MDM2 protein by immunohistochemical staining (14). Thus it is clear that overexpression of the MDM2 protein contributes to oncogenesis.

At least some of MDM2's transforming properties are a result of its ability to bind to and inhibit the functions of the p53 tumor suppressor protein (15-17). p53 causes G1 arrest or apoptosis and may enhance DNA repair in response to DNA damage (reviewed in ref. 18). An aberrant overexpression of MDM2 in cells containing wild-type p53 compromises p53-mediated responses and enhances the tumorigenic potential of the cell. 
Besides the transforming phenotype of MDM2 overexpression, MDM2 has normal p53dependent functions in vivo. One such function is essential for embryonic development; MDM2 null mouse embryos die shortly after or at the time of implantation, and this lethality is reversed by deletion of the $p 53$ gene. This result indicates that MDM2's first essential function is the inhibition of $\mathrm{p} 53$ activity during early embryonic development $(19,20)$. MDM2 may also perform a normal role in the p53 DNA damage response. As $\mathrm{p} 53$ protein levels rise after cellular insult, p53 acts as a transcriptional activator for genes involved in cell cycle arrest, apoptosis, and DNA repair (reviewed in ref. 18). In addition, p53 activates expression of MDM2, which in turn negatively regulates p53's transcriptional activity $(21,22)$. An autoregulatory feedback loop is thus formed, in which MDM2 may contribute to the regulation of p53-dependent growth arrest.

Several lines of evidence suggest that MDM2 may also have roles independent of p53, some of which may contribute to its oncogenic potential. While the $\mathrm{NH}_{2}$-terminus of MDM2 is sufficient for binding and inhibiting p53, the protein contains several other domains that are highly conserved at the amino acid level $(23,24)$. These include a central acidic domain required for interaction with the ribosomal subunit L5 and its associated $5 \mathrm{~S}$ ribosomal RNA, and a $\mathrm{COOH}$-terminal RING finger that mediates binding to specific structural or sequence motifs in RNA (25-27). In addition, MDM2 contains both nuclear import and nuclear export signal sequences and can shuttle back and forth between the nucleus and the cytoplasm (JCR, DAF, AJL unpublished data). The functional significance of these domains for cellular activities of MDM2 remains unclear.

Several additional observations indicate that MDM2 may have p53-independent functions. MDM2 has physical and functional interactions with the $\mathrm{pRB}$ tumor suppressor and with the E2F1/DP1 S phase-promoting transcriptional activator. MDM2's interaction with pRB disrupts the $\mathrm{pRb}-\mathrm{E} 2 \mathrm{~F}$ complex and releases functional E2F; its interaction with E2F increases E2F-dependent transcription $(28,29)$. Finally, a number of sarcomas, leukemias, and carcinomas have been described that harbor both p 53 mutations that inactivate its function and MDM2 protein overproduction (10-12). Individuals with such sarcomas had a much lower survival rate than those with sarcomas containing either one of the two alterations alone, suggesting that overexpression of MDM2 may have tumor-promoting functions that are independent of p53 (10).

In order to analyze the $\mathrm{p} 53$ binding domain of MDM2 and to create tools with which to separate p53-dependent and -independent MDM2 functions, a genetic approach was used. p53 and a fragment of MDM2 were co-expressed in yeast, and a genetic screen was performed to detect $M d m 2$ mutations that prevented interaction between the two proteins. The inability of the resulting mutant MDM2 proteins to interact with p53 was subsequently confirmed in vitro. Sitedirected mutagenesis was then performed to identify additional residues of MDM2 critical for p53 binding. Several of the mutant MDM2 proteins were tested in mammalian cell culture for their ability to bind p53 and inhibit p53-dependent transactivation of a luciferase reporter gene. Finally, analysis of the crystal structure of the MDM2-p53 complex indicates that two classes of $M d m 2$ mutations were generated: those that alter MDM2 residues that directly contact p53 and those that alter residues that play important structural roles for the MDM2 domain that binds to $\mathrm{p} 53$ (30).

\section{MATERIALS AND METHODS}

\section{Yeast Strain}

The Saccharomyces cerevisiae strain used for the isolation of $M d m 2$ mutations was YCE1086-15B (MATa trp1 leu2 ura3 his 3 ade2 isogenic with S288C), which had been modified by the integration of pCE136 (GAL $\left.{ }^{\mathrm{p}}: \mathrm{p} 53\right)$, and the intro-

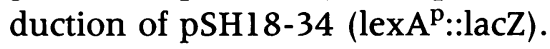

\section{Plasmids}

pSH18-34, a gift of S. Hanes and R. Brent, is a yeast episomal plasmid that places the lac $Z$ gene under the control of the lexA operator, (similar to plasmids described in 31). pCE136 is a yeastintegrating plasmid that expresses wild-type human p53 under the control of the GAL1/10 promoter. It was synthesized by cloning an existing GAL1/10::p53 promoter fusion into pRS405 (32) as an $X b a \mathrm{I} / H$ indIII fragment. The original GAL1/10::p53 promoter fusion was a gift of S. Ramos and J. Broach. pCE136 was integrated into YCE1086-15B by linearizing inside $L E U 2$ with AftII, followed by integrative transformation. The integrants were confirmed by Southern 
blotting and by demonstrating 2:2 segregation of leucine prototrophy following meiosis. To make pCE151, encoding the lexA::MDM2 fusion protein, human $M d m 2$ cDNA (23), a gift of J. Chen, was PCR amplified from codons -5 to 115 , and then cloned as an EcoRI-XhoI fragment into pEG202 (32), a gift of R. Brent and E. Golemis. The oligos used in the PCR amplification were $\left(5^{\prime}\right.$ oligo) GACTGAGAATTCGTGAGGAGCAG GCAAATG and ( $3^{\prime}$ oligo) GACTGACTCGAGCTA TGATTCCTGCTGATTGACTACTAC. The newly introduced restriction sites are underlined. pCE151 was mutagenized with hydroxylamine as described by Rose et al. (33).

\section{Western Analysis of Yeast Colonies}

Liquid cultures were grown in the appropriate selective media. $1.5 \mathrm{ml}$ of each culture was pelleted and resuspended in $50 \mu \mathrm{l}$ of $2 \times$ SDS sample buffer (125 mM Tris-HCL, pH 6.8; 4\% SDS; 30\% glycerol; $0.002 \%$ bromophenol blue; $2 \% \beta$-mercaptoethanol). Samples were then frozen at $-70^{\circ} \mathrm{C}$ and boiled for 5 min to lyse the cells. Half of each sample was run on $8 \%$ polyacrylamide gels and transferred to Hybond-ECL nitrocellulose (Amersham Life Sciences). Membranes were blocked for $1 \mathrm{hr}$ in wash buffer (PBS; $0.1 \%$ Tween 20 ) plus $5 \%$ milk, followed by a quick rinse in wash buffer. The membranes were then hybridized with a 2000-fold dilution of $\alpha$-lexA polyclonal sera (a gift from Erica Golemis) in wash buffer with $3 \%$ BSA. After several washes, the membranes were incubated with a 500-fold dilution of protein A-peroxidase (Boehringer Mannheim) in wash buffer plus 5\% milk. After extensive washing, lexA fusion proteins were visualized by ECL detection (Amersham Life Sciences). To control for loading of total protein in each lane, the membranes were then probed with a 5000-fold dilution of polyclonal sera against Kar2 protein (a gift from Mark Rose).

\section{Sequencing}

Approximately $5 \mu \mathrm{g}$ of each plasmid was sequenced using Sequenase Version 2.0 kits (U.S. Biochemical). Primers used were 5'-GAGCTTCA CCATTGAAGG-3' derived from the lexA coding sequence, 5'-TAAATCATAAGAAATTCG-3' from pCE151 sequences, and 5'GACTACTACCAAGTT CCTG-3' from $M d m 2$ sequence.

\section{In Vitro Labeling and Analysis of Translation Products}

$M d m 2$ fragments or full-length clones were expressed and $\left[{ }^{35} \mathrm{~S}\right]$-labeled in a coupled transcription and translation system (TNT Coupled Reticulocyte Lysate Systems from Promega), using T7 polymerase.

Immunoprecipitation of translation products was performed with 4-10 $\mu$ l of each labeled lysate and $30 \mu \mathrm{l}$ of $50 \%$ protein A-sepharose slurry with either $2 \mu \mathrm{l}$ of anti-human MDM2 polyclonal serum or $200 \mu \mathrm{l}$ of monoclonal antibodies (SV40 T antigen-specific 419 as a negative control; human MDM2-specific 3G5 and 4B2 [23]). Total volume was brought to $300 \mu \mathrm{l}$ with the addition of lysis buffer $(50 \mathrm{mM}$ Tris-HCL, $\mathrm{pH}$ 7.5; $150 \mathrm{mM} \mathrm{NaCl} ; 0.5 \%$ NP40; $1 \mathrm{mM}$ EDTA; added fresh: $1 \mathrm{mM}$ DTT, $100 \mu \mathrm{M}$ PMSF, $1 \mu \mathrm{M}$ Pepstatin, $1 \mu \mathrm{M}$ E-64). Tubes were then rotated at $4^{\circ} \mathrm{C}$ for at least $2 \mathrm{hr}$. Extensive washes were done, three with SNNTE ( $5 \%$ sucrose; $1 \%$ NP40; $0.5 \mathrm{M} \mathrm{NaCl} ; 50 \mathrm{mM}$ Tris- $\mathrm{HCl}, \mathrm{pH} 7.5 ; 5 \mathrm{mM}$ EDTA) and one with RIPA buffer (50 mM Tris$\mathrm{HCl}, \mathrm{pH} 7.5 ; 150 \mathrm{mM} \mathrm{NaCl} ; 1 \%$ Triton X-100; $0.1 \%$ SDS; $1 \%$ sodium deoxycholate). Proteins were eluted by boiling in SDS sample buffer and were then separated by SDS-PAGE and visualized by autoradiography.

Binding to p53 was assessed by incubating the same labeled lysates with $25 \mu \mathrm{g}$ of GST::p53 (1-82) or $25 \mu \mathrm{g}$ of negative control fusion GST::CSB (1-242) purified from E. coli on Glutathione Sepharose 4B (Pharmacia Biotech). Total volume was $400 \mu \mathrm{l}$, and they were rotated at room temperature for 2 to $3 \mathrm{hr}$. Three washes were performed with PBS and one with lysis buffer. The beads were resuspended in SDS sample buffer and boiled for $5 \mathrm{~min}$ before separation by SDS-PAGE. Results were visualized by autoradiography.

\section{Site-directed Mutagenesis of $\mathbf{M d m 2}$}

Site-directed mutagenesis was performed using the Transformer Site-Directed Mutagenesis Kit (Clontech). All clones were sequenced to verify that the correct mutation was made.

\section{Cell Culture and Transfection Techniques}

Saos- 2 cells were grown in DMEM plus 15\% fetal calf serum. Cells were transfected by electroporation with $1 \mu \mathrm{g}$ of luciferase reporter plasmid, $30 \mathrm{ng}$ of $\mathrm{pRC} / \mathrm{p} 53,3 \mu \mathrm{g}$ of $\mathrm{pCMV}$ plasmids 
(with wild-type, mutant, or no $M d m 2$ ), and $6 \mu \mathrm{g}$ of carrier DNA as follows. Approximately $1.2 \times$ $10^{6}$ cells in $0.4 \mathrm{ml}$ media were mixed with the DNA. Electroporation was performed on a Gene Pulser (BioRad) at $960 \mu \mathrm{FD}$ and $0.23 \mathrm{~V}$. Luciferase assays were performed $12 \mathrm{hr}$ after transfection using the Enhanced Luciferase Assay Kit (Analytical Luminescence Laboratory) as described in the protocols supplied by the manufacturer.

\section{Indirect Immunofluorescence}

Saos-2 cells were electroporated with $10 \mu \mathrm{g}$ of various pCMV plasmids as described above, and were plated into 6-well dishes with cover slips. Twelve hours following transfection, the cells were rinsed with PBS and fixed for $5 \mathrm{~min}$ in cold methanol. Cells were then rinsed several times with PBS, before a 20 -min block in $10 \%$ goat serum in BT-PBS (PBS with $0.1 \%$ Tween 20 and $1 \%$ BSA). Coverslips were then incubated for 50 min with 2A9 MDM2 monoclonal supernatants and washed extensively with BT-PBS. The secondary antibody, biotin-SP-conjugated goat antimouse IgG (Jackson ImmunoResearch Laboratories), was diluted 500 -fold in $10 \%$ goat serum BT-PBS and incubated on the cells for $40 \mathrm{~min}$. After extensive washing, the cells were incubated for 15 min with a 1000 -fold dilution of streptavidin-fluorescein isothiocyanate conjugate (Gibco BRL) and washed again. Cells were then mounted and viewed using a confocal microscope.

\section{RESULTS}

\section{Yeast Screen for MDM2 Mutants Deficient} in $\mathbf{p 5 3}$ Interaction

In order to find point mutations in $M d m 2$ that disrupt binding to $\mathrm{p} 53$, a genetic screen in yeast was performed. A yeast strain was produced in which human $\mathrm{p} 53$ is expressed under the control of a galactose-inducible promoter and which contains a yeast expression plasmid that places the $E$. coli lacZ gene under the control of a lexA operator (31). When this strain is transformed with a plasmid (called pCE151) that encodes a fusion between the DNA binding domain of lexA and the $\mathrm{NH}_{2}$-terminal 115 amino acids of human MDM2, the yeast express lacZ in a p53-dependent manner, as the $\mathrm{p} 53$ transcriptional activity is brought to the lexA operator through its inter-
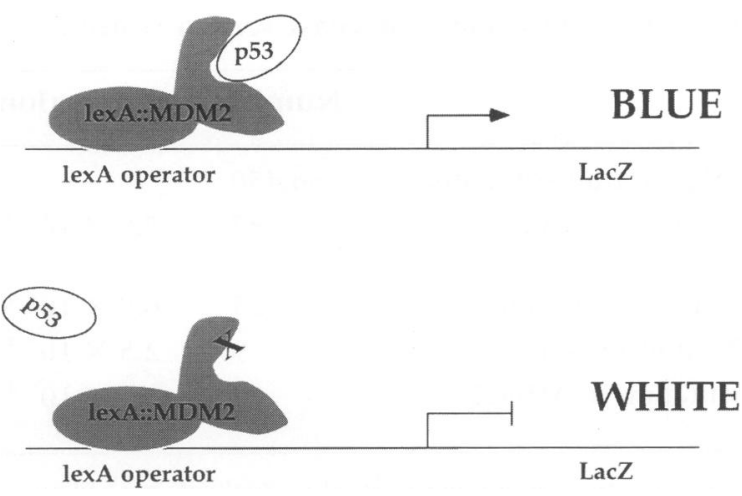

FIG. 1. Schematic of yeast screen used to isolate mutant MDM2 proteins unable to interact with p53

p53 is localized to the lacZ promoter by interaction with the lexA::MDM2 (1-115) fusion protein where it activates expression of lacZ. If a mutation (X) prevents the MDM2-p53 interaction, lacZ is not expressed.

action with the lexA::MDM2 fusion protein. $\mathrm{p} 53$ is transcriptionally active in the yeast cells despite its interaction with inhibitory MDM2, probably because there remain unblocked transcriptional activation sites in the tetramerized p53. Such yeast therefore express lac $Z$ and turn blue when galactose-induced in the presence of Xgal. Mutations in the lexA::MDM2 fusion protein that disrupt the MDM2-p53 interaction prevent lacZ expression, resulting in white colonies (Fig. 1).

The lexA::MDM2 expression plasmid (pCE151) was mutagenized in vitro with hydroxylamine and was transformed into the yeast strain described above. White colonies were picked and tested by Western analysis for the expression of full-length lexA::MDM2 fusion protein. When full-length fusion protein was detected, the potentially mutant derivative of pCE 151 was recovered and tested by retransformation into the original host strain to confirm that the white phenotype was linked to the plasmid. The complete sequence of the $M d m 2$ fragment was determined from nine plasmids derived from pCE151; five were identical to the wild-type sequence and may have had mutations in the lexA domain that prevented DNA binding. The other four plasmids sustained mutations in Mdm2 (Table 1). One mutant contained a twobase-pair deletion at codon 106. This frameshift causes a deletion of amino acids 106-115 of MDM2 and is predicted to add 18 new residues 
TABLE 1. Summary of yeast screen results

\begin{tabular}{lrr}
\hline & Number & Proportion \\
\hline $\begin{array}{l}\text { Original transformants } \\
\text { Colonies that retest }\end{array}$ & 36,450 & \\
$\quad$ white & 287 & $7.9 \times 10^{-3}$ \\
Full-length protein & 25 & $6.9 \times 10^{-4}$ \\
Plasmid-linked & 9 & $2.5 \times 10^{-4}$ \\
Mutation in MDM2 & 4 & $1.1 \times 10^{-4}$ \\
\hline
\end{tabular}

Transformants were replica plated to Xgal galactose plates, and white colonies were picked and retested. Western analysis was performed to verify expression of full-length fusion proteins, and the phenotype was shown to be plasmid-linked by plasmid isolation and retransformation into the original host strain. Sequencing of the MDM2 coding region revealed four separate mutations: G58D, C77Y (isolated twice), and $\Delta 106-115 /+18$.

derived from vector sequences $(\Delta 106-115 /+18)$. This change may affect folding of the fusion protein, or the extra peptide may sterically interfere with the MDM2-p53 interaction; it was therefore not pursued further. The other three mutations recovered included a cysteine to tyrosine change at amino acid 77 (C77Y, recovered twice) and a glycine to aspartate change at residue 58 (G58D). For the latter mutation, the DNA encoding the $M d m 2$ fragment was excised and recloned into the original cloning vector, transformed into yeast, and tested phenotypically. The failure to detect $\beta$-galactosidase activity confirmed that the G58D change was sufficient to cause the white phenotype.

\section{Testing of Mutant MDM2 1-115 Fragments In Vitro}

The inability of the G58D and C77Y mutant MDM2 1-115 fragments to bind p53 was verified in vitro, by excising the fragments from the yeast fusion plasmids and cloning them into Bluescript II KS (Stratagene). Wild-type and mutant MDM2 fragments, as well as luciferase as a negative control, were expressed and labeled in vitro with $\left[{ }^{35} \mathrm{~S}\right]$-methionine using TNT Coupled Reticulocyte Lysate Systems (Promega). Glutathione beads with either GST::p53 (amino acids 1-82) or a negative control GST::CSB (a DNA repair ATPase, amino acids 1-242) fusion protein were then used in an attempt to precipitate the labeled MDM2 fragments from the reticulocyte lysates.
After incubation, the beads were washed and the precipitated products were separated by SDSPAGE. While the wild-type (1-115) fragment of MDM2 is clearly able to bind specifically to the GST::p53 fusion and not to the negative control GST::CSB fusion protein, neither mutant MDM2 peptide showed any detectable level of binding to either p53 or the control fusion protein (Fig. 2A). Expression of the mutant peptides in the reticulocyte lysates was verified by immunoprecipitation (see below).

One possible explanation for the inability of the mutant MDM2 proteins to interact with p53 is misfolding of the mutant peptides. To address this concern, the mutant MDM2 fragments were tested for their recognition by two conformationdependent MDM2 monoclonal antibodies. Antibodies 4B2 and 3G5 have epitopes that map to the $\mathrm{NH}_{2}$-terminus of MDM2 (amino acids 6-58 and 58-89, respectively), and neither antibody recognizes the denatured form of the MDM2 protein (23). Interestingly, 3G5 can only bind to free MDM2 and cannot precipitate MDM2-p53 complexes, which suggests that its epitope is within the p53-binding site (23). These two monoclonal antibodies, MDM2-specific polyclonal sera and a monoclonal antibody that recognizes SV40 large T antigen (as a negative control) were used to immunoprecipitate the in vitro-labeled wild-type and mutant MDM2 fragments from the same lysates used in the p53binding assay described above. The MDM2 polyclonal sera but not the negative control antibody recognized the mutant and wild-type MDM2 proteins as expected. In addition, both MDM2specific conformation-dependent antibodies recognized the G58D and the C77Y mutants, as well as the wild-type protein, indicating that the two MDM2 mutant forms are not grossly misfolded (Fig. 2B).

\section{Site-directed Mutagenesis of Full-length $M d m 2$}

The $M d m 2$ mutations found in the yeast screen define residues in a highly conserved domain of the $\mathrm{NH}_{2}$-terminus of MDM2 (24; Fig. 3). Sitedirected mutagenesis was therefore performed in this region of the protein to identify additional amino acids that might play important roles in binding to $\mathrm{p} 53$. In addition, the mutations identified in the genetic screen were introduced into the full-length $M d m 2$ cDNA. Table 2 lists a summary of the mutations that were made in the full-length human $M d m 2$ cDNA and the results of 


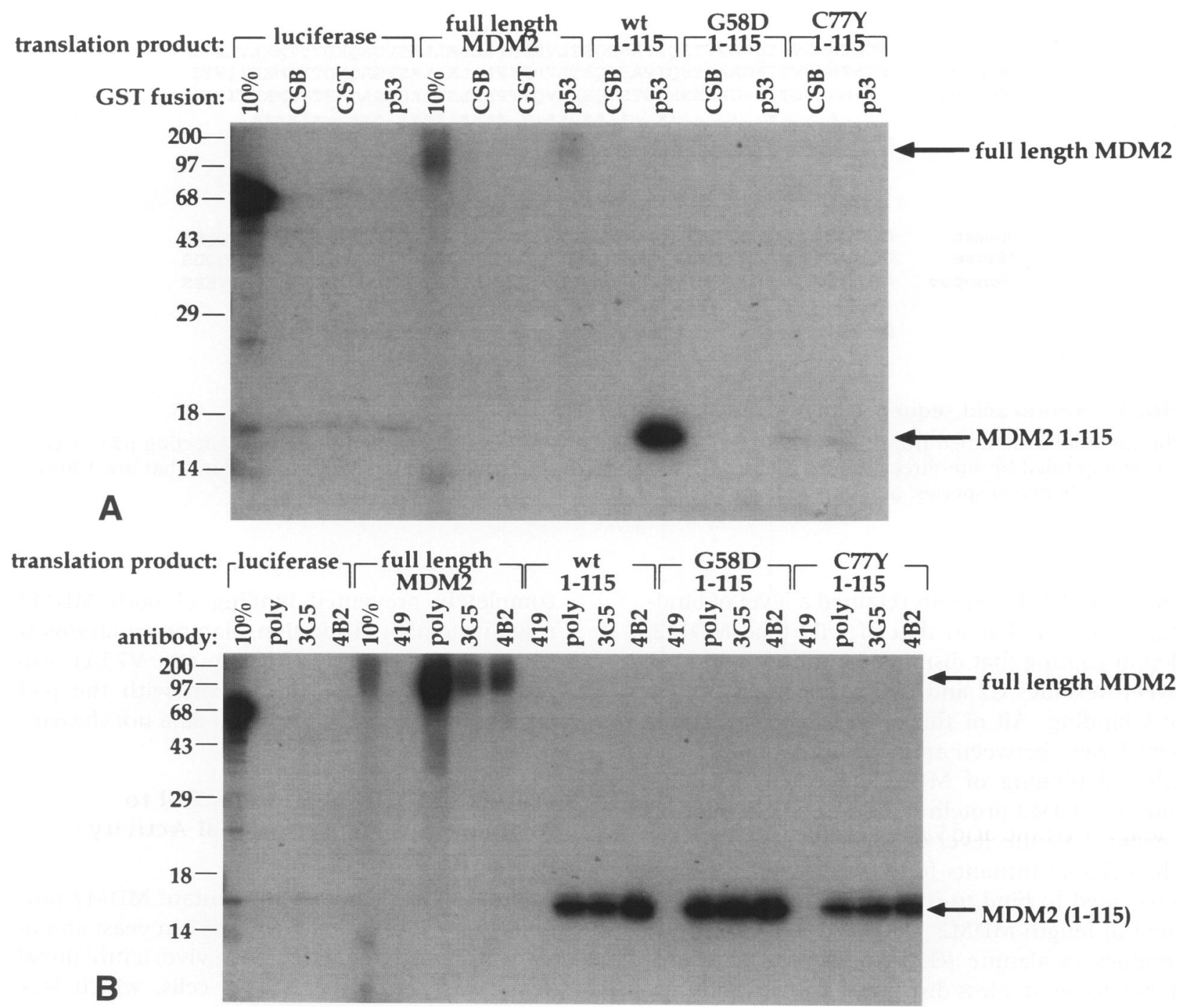

FIG. 2. Mutant MDM2 (1-115) fragments do not bind to 553 and react with two conformation-dependent antibodies in vitro

(A) Five different plasmids were translated and $\left[{ }^{35} \mathrm{~S}\right]$-labeled in vitro: luciferase as a negative control, full length and 1-115 of human wild-type $M d m 2$ as positive controls, and the two mutant $1-115$ fragments identified in the yeast screen. These translation products were then precipitated by incubation with GST-fusion proteins on glutathione beads and were separated on a 15\% SDS-polyacrylamide gel. CSB is a negative control fusion of amino acids 1-242 of CSB DNA repair ATPase to GST (GST::CSB (1-242)). p53 is a fusion of amino acids $1-82$ of p53 to GST (GST::p53 (1-82)). p53 failed to precipitate the mutant MDM2 proteins. (B) The same in vitro translation products used in A were immunoprecipitated as indicated and were separated on a 15\% SDS-polyacrylamide gel. "Poly" is polyclonal sera against MDM2; 419 is a negative control monoclonal antibody against SV40 T antigen; $3 \mathrm{G} 5$ and 4B2 are MDM2-specific monoclonal antibodies that do not recognize denatured protein. Both mutant proteins were recognized by the conformation-dependent antibodies, which suggests that they are properly folded. Molecular weight markers in $\mathrm{kD}$ are shown along left side.

a p53-binding assay performed with $\left[{ }^{35} \mathrm{~S}\right]-\mathrm{la}$ beled mutant MDM2 proteins. The binding assay of MDM2 to $\mathrm{p} 53$ was performed as described for the MDM2 1-115 fragments (as in Fig. 2A). In one case, the cysteine at residue 2 of MDM2 was changed to alanine. This change was made to test the possibility that $\mathrm{C} 77$, which was mutated to tyrosine in the yeast mutant screen, forms a disulfide bond with $\mathrm{C} 2$ that is required for the MDM2-p53 interaction. The C2A mutation would interfere with disulfide bond formation and therefore would also disrupt binding to p53. 


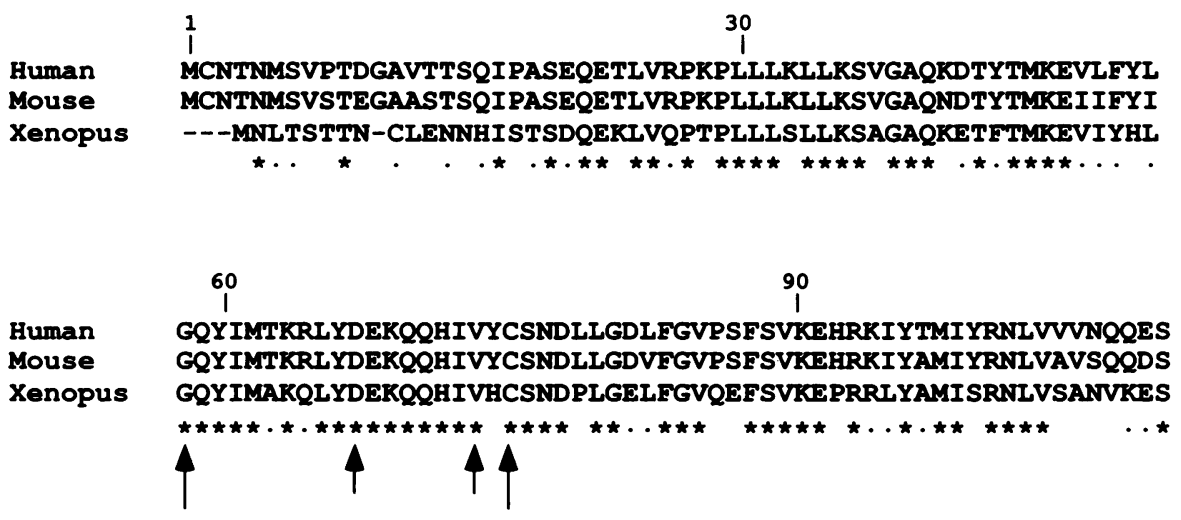

FIG. 3. Amino acid sequence alignment of MDM2 1-115

The mutations identified from the yeast screen are indicated with large arrows and mutations affecting $\mathrm{p} 53$ interaction identified by site-directed mutagenesis are shown with small arrows. Stars indicate residues that are $100 \%$ conserved between species, and dots indicate that the amino acids are of similar character.

The C2A MDM2 mutant retained a level of binding to p53 similar to that of wild-type MDM2, demonstrating that disulfide bond formation between residues $\mathrm{C} 2$ and $\mathrm{C} 77$ is not necessary for p53 binding. All of the other $M d m 2$ mutations tested were between amino acids 58 and 77 and affected binding of MDM2 to p53. The E69A mutant MDM2 protein bound to $\mathrm{p} 53$ at approximately half the level of the wild-type protein. The original mutants found in the yeast screen also failed to bind to p53 when introduced into the full-length MDM2 protein. Changes of these residues to alanine (G58A and C77A) are predicted to be of a less disruptive nature, and they completely prevented binding of both MDM2 mutants to $\mathrm{p} 53$. In addition, alanine mutations at residues D68 and V75 (D68A and V75A) also prevented detectable interaction with the p53 protein in this assay (Fig. 4 and data not shown).

\section{Full-length MDM2 Mutants Fail to Regulate the Transcriptional Activity of p53 In Vivo}

In order to test whether the mutant MDM2 proteins that fail to interact with $\mathrm{p} 53$ in yeast and in vitro also fail to regulate $\mathrm{p} 53$ in vivo, a functional assay was performed. Saos-2 cells, which lack

TABLE 2. Summary of mutagenesis and binding assays with MDM2

\begin{tabular}{llccc}
\hline Mutant & \multicolumn{1}{c}{ Derivation } & Ab-reactivity & p53 Binding & In Vivo Regulation \\
\hline wt & & + & ++ & + \\
C2A & S.D. mutagenesis & ND & ++ & ND \\
G58D & Yeast screen & + & - & ND \\
G58A & S.D. mutagenesis & ND & - & - \\
D68A & S.D. mutagenesis & ND & - & - \\
E69A & S.D. mutagenesis & ND & + & ND \\
V75A & S.D. mutagenesis & ND & - & - \\
C77Y & Yeast screen & + & - & ND \\
C77A & S.D. mutagenesis & ND & - & ND \\
& & & & \\
\hline
\end{tabular}

Eight MDM2 mutant proteins were made by site-directed mutagenesis and tested for the ability to bind to GST::p53 (1-82) (Figs. 2A and 4 and data not shown). Two retained full or partial binding ability (C2A and E69A), while the other six resulted in proteins that could not detectably interact with p53. Ab-reactivity is shown in Fig. $2 \mathrm{~B}$ and in vivo regulation in Fig. 5. S.D., sitedirected; ND, not determined. 


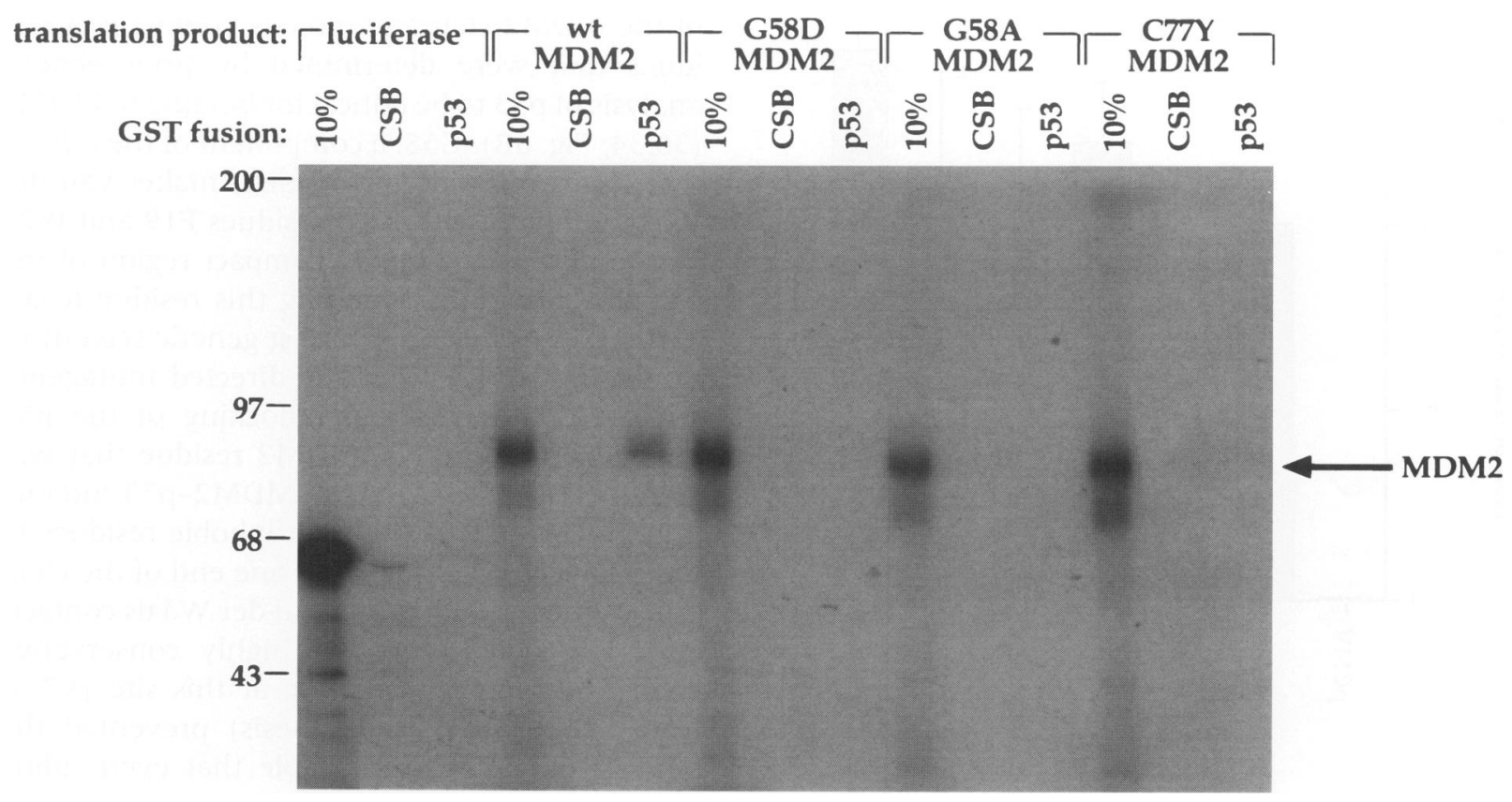

FIG. 4. Full-length mutant MDM2 proteins do not bind to p53 in vitro

Plasmids were labeled and translated in vitro as described in Materials and Methods. The translation products were then precipitated with GST fusion proteins as in Fig. 2A. Luciferase is used as a negative control, as is GST::CSB (1-242). Ten percent of the labeled input is loaded as a control. Only the wild-type MDM2 protein is precipitated by the GST::p53 (1-82) protein. Molecular weight markers in kD are shown along the left side.

endogenous p53, were transiently transfected with a human p53-expressing plasmid and a p53-responsive luciferase reporter plasmid (BP100-GL2, containing the p53-binding element of the $M d m 2$ promoter). In addition, the cells were transfected with either an empty vector or with wild-type or mutant human MDM2expressing plasmids, created by site-directed mutagenesis of pCHDM1A (16). Wild-type MDM2 blocked p53-dependent transactivation by approximately 5 -fold as previously reported (16), while the $\triangle 58-89$ MDM2 deletion mutant failed to do so (Fig. 5). The G58A, D68A, and V75A mutant MDM2 proteins also failed to inhibit $\mathrm{p} 53$ transcriptional activity in this assay, verifying the inability of the mutant MDM2 proteins to bind to p53. Similar results were also obtained using another p53-responsive luciferase reporter containing the $\mathrm{p} 21^{\text {wafl }} \mathrm{p} 53$-responsive element (pWWPGL2). These results show that the point mutations identified here disrupt MDM2's ability to regulate p53's transactivation of p53-responsive genes, which is consistent with indications that a physical interaction between the two proteins is required for MDM2's inhibition of p53 activity.

The expression and proper localization of these inactive MDM2 mutant proteins were ver- ified by indirect immunofluorescence. Wild-type and mutant MDM2 proteins were detected in approximately the same percentage of cells in each transfected population. In addition, mutant MDM2 proteins were localized to the nucleus as was the wild-type protein (data not shown).

\section{Analysis of a Crystal Structure of the MDM2-p53 Complex}

The residues defined here as critical for MDM2p53 binding using mutational analysis correspond well with the residues identified to be important from the crystal structure of the $\mathrm{NH}_{2}$ terminus of human MDM2 (amino acids 17 to 125 ) bound to amino acids 15 to 29 of human p53 (30; Fig. 6A). In this structure, the MDM2 domain contains a deep cleft lined with hydrophobic and aromatic amino acids. The p53 peptide forms an amphipathic $\alpha$ helix that fits directly into the cleft and makes several hydrophobic contacts with MDM2. Two of the amino acids identified in this report play structural roles in the MDM2 domain. C77 is buried in the hydrophobic core of the middle $\beta$ sheet that caps one end of the MDM2 cleft. The occurrence of a tyrosine at this site, as in the yeast screenderived $\mathrm{C} 77 \mathrm{Y}$, may expand this compact region, 


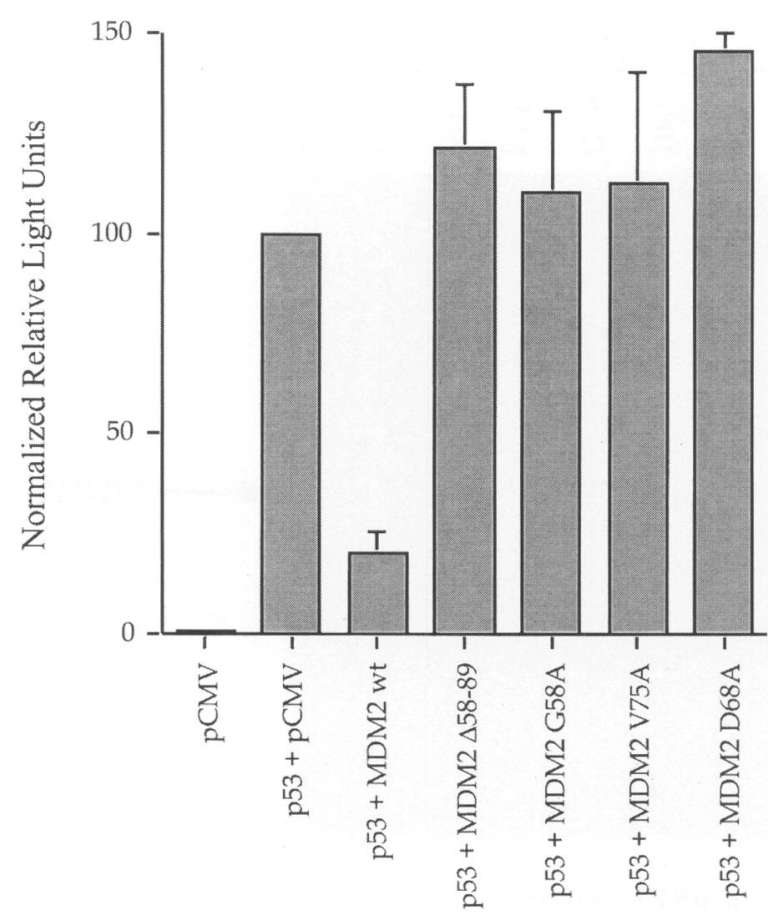

FIG. 5. Mutant MDM2 proteins are unable to inhibit p53-dependent transcription in fibroblasts

Saos- 2 cells were transiently transfected by electroporation with a p53 expression plasmid (pRC/p53), with a p53-dependent luciferase reporter plasmid (BP100-GL2), and with either an empty vector or with wild-type or mutant $M d m 2$ expression plasmids as indicated. The luciferase activity in the various cell lysates was quantitated. Shown is the average of three separate experiments and the standard error of the mean. Only the wild-type MDM2 protein was able in inhibit p53-dependent transcriptional activation.

perhaps altering the conformation of the cleft. The C77A mutation also prevented MDM2's interaction with $\mathrm{p} 53$, demonstrating that this mutation may also alter the hydrophobic core of this domain. The second residue that plays a structural role in MDM2 is D68. This residue is predicted to form three intramolecular hydrogen bonds: two involving the backbone nitrogens of E69 and K70, and one involving the tyrosine side chain of residue 76 . These interactions likely help stabilize the middle $\beta$ sheet, the other face of which contacts p53. Alteration of this residue from aspartic acid to alanine (D68A) would prevent formation of these hydrogen bonds, possibly destabilizing the MDM2 cleft and preventing productive interaction with p53 (Fig. 6A).

The other two residues identified in this mutational analysis as important for the MDM2-p53 interaction are found in the hydrophobic lining of the MDM2 cleft and directly contact p53 residues that were determined by prior genetic analysis of $\mathrm{p} 53$ to be critical for binding to MDM2 (30,34; Fig. 6B). G58, a component of the $\alpha$ helix that forms one side of the cleft, makes van der Waals contacts with both residues F19 and W23 of p53 and is in a highly compact region of the complex (Fig. 6B). Mutating this residue to aspartic acid (G58D of the yeast genetic screen) or to alanine (G58A from site-directed mutagenesis) could prevent proper docking of the p53 peptide. An additional MDM2 residue that was identified as critical for the MDM2-p53 interaction is V75, one of the hydrophobic residues of the middle $\beta$ sheet that caps one end of the cleft. This valine residue makes van der Waals contacts with F19 of p53. As the highly conservative change of valine to alanine at this site (V75A from site-directed mutagenesis) prevented the binding of p53, it is probable that even subtle changes in this hydrophobic pocket of the $\mathrm{NH}_{2}$ terminus of MDM2 are sufficient to destabilize the interaction between MDM2 and p53 (Fig. 6B).

\section{DISCUSSION}

The best-studied activities of the MDM2 oncoprotein are its interaction with p53 and its inhibition of p53-dependent transcription, both of which are mediated by the $\mathrm{NH}_{2}$-terminus of MDM2 (23). To better define the amino acids of MDM2 required for this interaction with $\mathrm{p} 53$, a genetic screen in yeast was employed to select mutations in MDM2 which interfered with its ability to bind p53. This method proved fruitful, identifying two residues that were important for this protein-protein interaction (G58D and C77Y of MDM2). Although the mutant screen certainly did not saturate the gene for all possible mutations affecting p53 binding, the mutations that were found helped to define a smaller region that was then further altered by site-directed mutagenesis. Two of the three additional residues altered in this region proved to be critical for the MDM2-p53 interaction.

The mutant MDM2 proteins were tested for their ability to bind to p53 in vitro. One mutation residing outside of the region defined by the screen did not prevent binding to p53 (i.e., the C2A mutation). This result eliminated the possibility that a disulfide bond between residues $\mathrm{C} 2$ and C77 of MDM2 is critical for interaction with p53. All mutations that were made between residues 58 and 77 affected the interaction of 

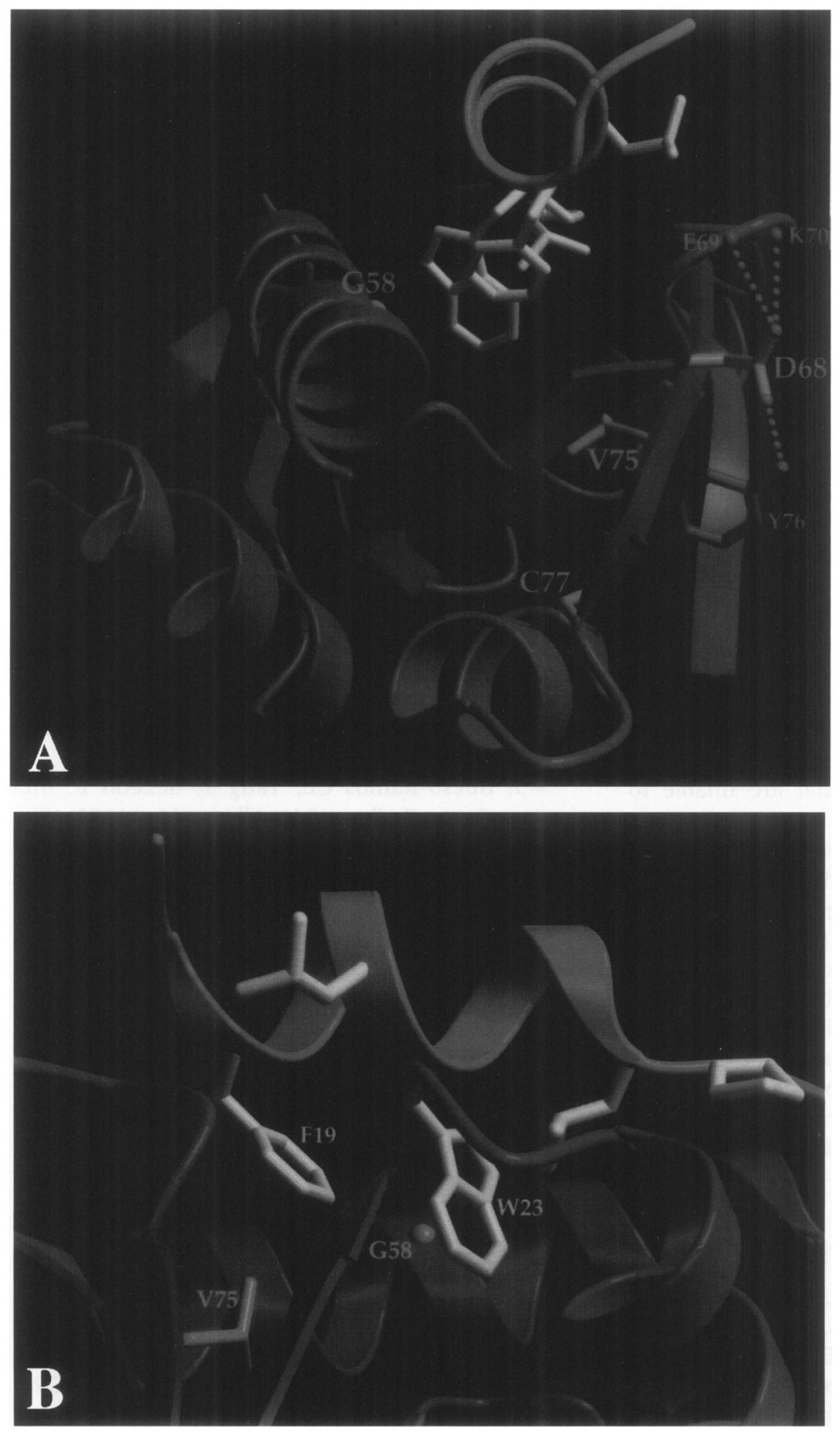

FIG. 6. Crystal structure of the MDM2-p53 complex

(A) The p53 peptide (amino acids 15 to 29) is the small helix at the top. The

MDM2 fragment (amino acids 17 to 125 ) is the large structure at the bottom that forms a deep cleft. Selected side chains are shown.

Playing structural roles are residue C77 of MDM2,

which is buried in a hydrophobic region and D68, which is predicted to form three intramolecular hydrogen bonds as shown. Two hydrogen bonds to backbone nitrogens of E69 and K70 and one to the Y76 side chain stabilize the middle $\beta$ sheet, the other face of which contacts p53. (B) $A$ view rotated approximately 90 degrees clockwise from that shown in A has the p53 helix at the top and part of MDM2 at the bottom. Two MDM2 residues identified as critical for the MDM2-p53 interaction by mutagenesis directly contact p53. V75 makes van der Waals contacts with F19 of p53, while G58 makes van der Waals contacts with both residues F19 and W23 of p53.
MDM2 with p53. The E69A mutant retained approximately $50 \%$ of the wild-type binding ability, while the other mutants did not bind p53 to a detectable level. These mutations include the likely less disruptive changes to alanine at the critical residues originally found in the yeastbased screen (G58A and C77A), an aspartic acid to alanine change at residue 68 (D68A), as well as the highly conservative change of valine to alanine at residue 75 (V75A). 
Several of the $M d m 2$ mutations (G58A, D68A, and V75A) were made in the $M d m 2$ cDNA in mammalian expression vectors by site-directed mutagenesis to test them in vivo for their abilities to functionally interact with p53. All three of these mutant MDM2 proteins failed to inhibit p53-dependent transcriptional activation in a transient transfection system. These results indicate that the MDM2 mutations described here indeed prevent MDM2 from regulating $\mathrm{p} 53$.

The MDM2 protein's p53-binding domain is highly conserved between human, mouse, and Xenopus laevis (24; Fig. 3). All of the residues shown to be important by the genetic approach described here are conserved between these three species. Since this work was initiated, the crystal structure of this MDM2-p53 complex has been determined (30). The genetic and physical approaches produced complimentary results. Two of the residues identified in the genetic screen play structural roles in MDM2's p53-binding domain, while two residues line the hydrophobic pocket of MDM2 and directly contact p53.

MDM2 may well have p53-independent functions, some of which may be relevant to its role in oncogenesis. It will be interesting to determine if MDM2 mutants that are unable to bind and regulate p53 retain any transforming ability in wild-type p53-containing cells (3). The other possible functions of MDM2 in $\mathrm{pRb}$ and E2F binding $(28,29)$, binding to the ribosomal protein L5-5S RNA complex (25), shuttling between the nucleus and the cytoplasm (JCR, DAF, AJL unpublished data), and binding to specific RNA structures (27) indicate that there are novel functions of MDM2 that remain to be explored. The mutant MDM2 proteins described here should prove useful in separating the p53-dependent and -independent roles of MDM2.

\section{ACKNOWLEDGMENTS}

We thank R. Brent, J. Broach, J. Chen, E. Golemis, S. Hanes, H. Lu, S. Ramos, and B. Vogelstein for plasmids. We also thank E. Golemis and M. Rose for the polyclonal antibodies used in the yeast screen. Lastly, we thank P. Kussie and N. Pavletich for helpful discussions, for sharing data prior to publication, and for assistance with figures.

This work was supported by an NIH Program Project Grant to A.J.L., PO1CA41086. D.A.F. was supported by an NIH Cellular and Molecular Training Grant, 5T32GM07312. C.B.E. was supported by a Cancer Research Fund of the Damon
Runyon-Walter Winchell Foundation Fellowship, DRG-1235. J.C.R. was supported by a fellowship from the German Research Foundation (DFG).

\section{REFERENCES}

1. Cahilly-Snyder L, Yang-Feng T, Francke U, George DL. (1987) Molecular analysis and chromosomal mapping of amplified genes isolated from a transformed mouse 3T3 cell line. Somat. Cell Mol. Gen. 13:235-244.

2. Fakharzadeh SS, Trusko SP, George DL. (1991) Tumorigenic potential associated with enhanced expression of a gene that is amplified in a mouse tumor cell line. $E M B O$ J. 10:1565-1569.

3. Finlay CA. (1993) The $m d m-2$ oncogene can overcome wild-type p53 suppression of transformed cell growth. Mol. Cell. Biol. 13: 301-306.

4. Oliner JD, Kinzler KW, Meltzer PS, George DL, Vogelstein B. (1992) Amplification of a gene encoding a p53-associated protein in human sarcomas. Nature 358:80-83.

5. Bueso-Ramos CE, Yang Y, deLeon E, McCown P, Stass SA, Albitar M. (1993) The human MDM-2 oncogene is overexpressed in leukemias. Blood 82:2617-2623.

6. Ladanyi $M$, Cha $C$, Lewis $R$, Jhanwar SC, Huvos AG, Healey JH. (1993) MDM2 gene amplification in metastatic osteosarcoma. Cancer Res. 53:16-18.

7. Leach FS, Tokino T, Meltzer P, et al. (1993) $p 53$ mutation and MDM2 amplification in human soft tissue sarcomas. Cancer Res. 53:22312234.

8. Reifenberger G, Liu L, Ichimura K, Schmidt EE, Collins VP. (1993) Amplification and overexpression of the $M D M 2$ gene in a subset of human malignant gliomas without $p 53$ mutations. Cancer Res. 53:2736-2739.

9. Sheikh MS, Shao Z-M, Hussain A, Fontana JA. (1993) The p53-binding protein MDM2 gene is differentially expressed in human breast carcinoma. Cancer Res. 53:3226-3228.

10. Cordon-Cardo C, Latres E, Drobnjak M, et al. (1994) Molecular abnormalities of $m d m 2$ and $p 53$ genes in adult soft tissue sarcomas. Cancer Res. 54:794-799.

11. Matsumura $T$, Yoshihama $Y$, Kimura $T$, Shintani S, Alcalde RE. (1996) p53 and MDM2 expression in oral squamous cell carcinoma. Oncology 53:308-312.

12. Watanabe $T$, Hotta $T$, Ichikawa $A$, et al. 
(1994) The MDM2 oncogene overexpression in chronic lymphocytic leukemia and lowgrade lymphoma of B-cell origin. Blood 84: 3158-3165.

13. Landers JE, Haines DS, Strauss JF, George DL. (1994) Enhanced translation: A novel mechanism of $m d m 2$ oncogene overexpression identified in human tumor cells. Oncogene 9:2745-2750.

14. Picksley SM, Spicer JF, Barnes DM, Lane DP. (1996) The p53-MDM2 interaction in a cancer-prone family, and the identification of a novel therapeutic target. Acta Oncologica 35: 429-434.

15. Momand J, Zambetti GP, Olson, DC, George D, Levine AJ. (1992) The $m d m-2$ oncogene product forms a complex with the $\mathrm{p} 53$ protein and inhibits p53-mediated transactivation. Cell 69:1237-1245.

16. Chen J, Lin J, Levine AJ. (1995) Regulation of transcription functions of the p53 tumor suppressor by the mdm-2 oncogene. Mol. Med. 1:142-152.

17. Chen J, Wu X, Lin J, Levine AJ. (1996) mdm-2 inhibits the $G_{1}$ arrest and apoptosis functions of the p53 tumor suppressor protein. Mol. Cell. Biol. 16:2445-2452.

18. Ko LJ, Prives C. (1996) p53: Puzzle and paradigm. Genes Dev. 10:1054-1072.

19. Montes de Oca Luna R, Wagner DS, Lozano G. (1995) Rescue of early embryonic lethality in $m d m 2$-deficient mice by deletion of p53. Nature 378:203-206.

20. Jones SN, Roe AE, Donehower LA, Bradley A. (1995) Rescue of embryonic lethality in $\mathrm{Mdm} 2$-deficient mice by absence of $\mathrm{p} 53$. $\mathrm{Na}$ ture 378:206-208.

21. Wu X, Bayle JH, Olson D, Levine AJ. (1993) The p53-mdm-2 autoregulatory feedback loop. Genes Dev. 7:1126-1132.

22. Perry ME, Piette J, Zawadzki JA, Harvey D, Levine AJ. (1993) The mdm-2 gene is induced in response to UV light in a p53-dependent manner. Proc. Natl. Acad. Sci. U.S.A. 90:11623-11627.

23. Chen J, Marechal V, Levine AJ. (1993) Mapping of the p53 and mdm-2 interaction domains. Mol. Cell. Biol. 13:4107-4114.

24. Marechal V, Elenbaas B, Taneyhill L, et al.
(1997) Conservation of structural domains and biochemical activities of the MDM2 protein from Xenopus laevis. Oncogene 14:14271433.

25. Marechal V, Elenbaas B, Piette J, Nicolas J-C, Levine AJ. (1994) The ribosomal L5 protein is associated with mdm-2 and mdm-2-p53 complexes. Mol. Cell. Biol. 14:7414-7420.

26. Boddy MN, Freemont PS, Borden KLB. (1994) The p53-associated protein MDM2 contains a newly characterized zinc-binding domain called the RING finger. Trends Biochem. Sci. 19:198-199.

27. Elenbaas B, Dobbelstein M, Roth J, Shenk T, Levine AJ. (1996) The MDM2 oncoprotein binds specifically to RNA through its RING finger domain. Mol. Med. 2:439-451.

28. Xiao Z-X, Chen J, Levine AJ, et al. (1995) Interaction between the retinoblastoma protein and the oncoprotein MDM2. Nature 375:694-698.

29. Martin K, Trouche D, Hagemeier C, Sorensen TS, La Thangue NB, Kouzarides T. (1995) Stimulation of E2F1/DP1 transcriptional activity by MDM2 oncoprotein. Nature 375:691-694.

30. Kussie PH, Gorina S, Marechal V, et al. (1996) Structure of the MDM2 oncoprotein bound to the p53 tumor suppressor transactivation domain. Science 274:948-953.

31. Gyuris J, Golemis E, Chertkov H, Brent R. (1993) Cdil, a human Gl - and S-phase protein phosphatase that associates with Cdk2. Cell 75:791-803.

32. Sikorski RS, Hieter P. (1989) A system of shuttle vectors and yeast host strains designed for efficient manipulation of DNA in Saccharomyces cerevisiae. Genetics 122:19-27.

33. Rose M, Winston F, Hieter P. (1990) Methods in Yeast Genetics: A Laboratory Course Manual. Cold Spring Harbor Laboratory Press, Cold Spring Harbor, NY.

34. Lin J, Chen J, Elenbaas B, Levine AJ. (1994) Several hydrophobic amino acids in the p53 amino-terminal domain are required for transcriptional activation, binding to $\mathrm{mdm}-2$ and the adenovirus $5 \mathrm{E} 1 \mathrm{~B} 55-\mathrm{kD}$ protein. Genes Dev. 8:1235-1246.

Communicated by A. Levine. Accepted January 29, 1997. 